Revista Eletrônica do Mestrado em Educação Ambiental

\title{
INFLUÊNCIA DO PERFIL DO COLEGIADO NA PRIORIZAÇÃO DE AÇÕES AMBIENTAIS NOS TERRITÓRIOS DA CIDADANIA DE SERGIPE
}

\author{
André Luiz Rodrigues de Albuquerque Omena ${ }^{1}$ \\ Daniela Venceslau Bitencourt ${ }^{2}$
}

Resumo: O estado de Sergipe possui quatro Territórios da Cidadania (Alto Sertão, Baixo São Francisco, Sertão Ocidental e Sul Sergipano), cujas ações estratégicas constam de seus respectivos Planos Territoriais de Desenvolvimento Rural Sustentável (PTDRS), elaborados pelo Colegiado Territorial (CT), composto por representantes das três esferas governamentais e da sociedade.Considerando que tal documento se revela como instrumento capazde expressar não apenas as particularidades locais, mas também os interesses e visão de quem o constrói, este artigo propõe uma reflexão sobre a relação entre o perfil dos membros dos CT e a contribuição dos PTDRS no que diz respeito à questão ambiental. Os dados obtidos permitem afirmar que as ações mais estruturadas nessa dimensão estão presentes nos territórios onde os representantes possuem algum tipo de engajamento e prática a ela relacionada.

Palavras-chave: sustentabilidade; colegiados; planos.

\section{INFLUENCIA DEL PERFIL DEL COLEGIADO EN LA PRIORIZACIÓN DE ACCIONES AMBIENTALES EN LOS TERRITORIOS DE LA CIUDADANÍA DE SERGIPE}

Resumen: El estado de Sergipe posee cuatro Territorios de la Ciudadanía (Alto Sertão, Baixo São Francisco, Sertão Occidental y Sur Sergipano), cuyas acciones estratégicas constan de sus respectivos Planes Territorios de Desarrollo Rural Sostenible (PTDRS), elaborados por el Colegio Territorial (CT), compuesto por representantes de las tres esferas gubernamentales y de la sociedad. Considerando que tal documento se revela como instrumento capaz de expresar no sólo las particularidades locales, sino también los intereses y visión de quien lo construye, este artículo

\footnotetext{
${ }^{1}$ Mestrando em Desenvolvimento e Meio Ambiente pela Universidade Federal de Sergipe (2017-2019). Pesquisador do Grupo de Pesquisa Formação Interdisciplinaridade e Meio Ambiente, na Universidade Federal de Sergipe (UFS). Possui graduação em Administração de Empresas, com habilitação em Comércio Exterior. Contato: mudinhofase@ gmail.com

${ }^{2}$ Doutora em Desenvolvimento e Meio Ambiente, possui graduação em Administração pela Faculdade de Administração e Negocios de Sergipe (2003), mestrado em Desenvolvimento e Meio Ambiente pela Universidade Federal de Sergipe (2008). Contato: daniela.aju@ @otmail.com
} 
propone una reflexión sobre la relación entre el perfil de los miembros de los CT y la contribución de los PTDRS en lo que se refiere a la cuestión medioambiental. Los datos obtenidos permiten afirmar que las acciones más estructuradas en esa dimensión están presentes en los territorios donde los representantes poseen algún tipo de compromiso y práctica relacionada con ella.

Palabras clave: sostenibilidad; colegiada; planes.

\title{
INFLUENCE OF THE COLLEGE PROFILE IN THE PRIORITIZATION OF ENVIRONMENTAL ACTIONS IN THE TERRITORIES OF SERGIPE CITIZENSHIP
}

\begin{abstract}
The State of Sergipe has four Territories of Citizenship (Alto Sertão, Baixo São Francisco, Sertão Oeste and Sergipano Sul), whose strategic actions are included in its Territorial Plans for Sustainable Rural Development (PTDRS), prepared by the Territorial Collegiate by representatives of the three governmental spheres and of society. Considering that such a document proves to be an instrument capable of expressing not only the local particularities but also the interests and vision of those who construct it, this article proposes a reflection on the relationship between the profile of the members of the TCs and the PTDRS contribution with regard to the environmental issue. The data obtained allow us to affirm that the most structured actions in this dimension are present in the territories where the representatives have some type of engagement and practice related to it.
\end{abstract}

Keywords: sustainability; collegiate; plans.

\section{Introdução}

O Programa Territórios da Cidadania (PTC), lançado no ano de 2008 como componente fundamental da agenda social do Governo Federal, representa uma estratégia que visa o alcance do desenvolvimento regional sustentável e a garantia de direitos sociais voltado às regiões mais pobres do país, com objetivo de atingir o desenvolvimento econômico e universalizar os programas básicos de cidadania (MDA, 2016).

Adotada pela Secretaria de Desenvolvimento Territorial, ligada ao Ministério do Desenvolvimento Agrário, a concepção de território rural aglutina contribuições colhidas no país e no exterior que a concebem como uma estratégia de gestão pública de programas de desenvolvimento rural sustentável (SILVA JUNIOR, 2015).

A iniciativa de criação dos territórios da cidadania tomou como base a integração entre os governos federais, estaduais e municipais, por meio da construção de um Plano Territorial de Desenvolvimento Rural Sustentável (PTDRS), específico para cada território e elaborado com a participação da sociedade, cuja implementação e o cumprimento de uma agenda pactuada de ações conta com a participação de colegiados territoriais compostos pelas três esferas governamentais e pela sociedade (MDA, 2016). 
Segundo a mesma fonte, para a formação dos territórios igualmente levou-se em consideração conjuntos de municípios unidos por semelhanças econômicas, ambientais, sociais, culturais e geográficas, de forma a facilitar o planejamento de ações governamentais para o desenvolvimento das regiões nas quais estes estão inseridos.

Devido às suas características, o PTC é compreendido como um modelo que se opõe à visão reducionista do sujeito, tendo como finalidade a adoção de um estilo de desenvolvimento que privilegia a sustentabilidade econômica, social e ambiental, apresentando-se como uma estratégia de inovação territorial e da gestão da política, ainda em construção (SANTOS; COSTA, 2013).

O estado de Sergipe conta com quatro territórios da cidadania, a saber: Alto Sertão, Baixo São Francisco, Sertão Ocidental e Sul Sergipano. Juntos esses territórios englobam 52 municípios, os quais perfazem uma área de $17.508 \mathrm{~km}^{2}$, onde vivem 1.006 .075 pessoas, das quais 447.429 se encontram no meio rural. Nos quatro territórios contabiliza-se 199.795 agricultores familiares, 7.198 famílias assentadas, 11.026 pescadores, 09 comunidades quilombolas e 01 terra indígena (MDA, 2016).

Os recursos iniciais destinados aos quatro territórios foram na ordem de R\$ 516.662.361,29, investidos em ações relativas a temas como direitos, desenvolvimento social, organização sustentável da produção, saúde, saneamento e acesso à água, educação e cultura, além de apoio à gestão territorial e infraestrutura. O Índice de Desenvolvimento Humano (IDH) médio/ano desses territórios é consideravelmente baixo $(0,60)$, sendo o Território do Alto Sertão o que apresenta menor resultado $(0,58)$ (SOBRAL; GOMES, 2013).

Cabe, no entanto, ressaltar que embora o Programa tenha ampla abrangência no estado, haja vista somente 23 dos 75 municípios sergipanos terem ficado de fora, verificase que as ações ambientais constantes dos PTDRS dos quatro territórios da cidadania de Sergipe diferem significativamente entre si, tanto em quantidade como em qualidade, suscitando dúvidas sobre as razões pelas quais foram priorizadas.

Com base nessa realidade, busca-se neste artigo refletir sobre a relação entre o envolvimento dos membros do Colegiados Territoriais (CT) de cada um dos territórios da cidadania de Sergipe com as questões ambientais, analisando a influência dessa atuação com a priorização das ações ambientais contidas nas matrizes de ação dos PTDRS.

A opção pela análise da dimensão ambiental deve-se especialmente a dois fatores. O primeiro é o entendimento de que esse é um componente essencial à sustentabilidade dos 
territórios rurais e o outro é a fragilidade constatada por autores que realizaram trabalhos voltados a avaliação desse aspecto na esfera do Programa em outros territórios do país.

Também não se pretende com a priorização do viés ambiental deixar de lado as demais dimensões (sociocultural, econômica, institucional), que são igualmente importantes e de alguma forma se perpassam e se articulam, mas reconhecer que a construção de um modelo de desenvolvimento voltado à sustentabilidade requer a compreensão dessa dimensão como ponto de partida para as demais análises.

\section{O processo de formação dos territórios da cidadania}

As primeiras propostas de estruturação regional surgidas entre os anos de 19501970 do século passado, conduzidas por políticas verticalizadas ou de fora para dentro, serviu de base para a construção das sociedades industrializadas. Dos anos setenta em diante, passaram a ser adotados modelos de desenvolvimento regional que se tornaram comuns em diversos países e influenciaram as estratégias para os espaços rurais (ECHEVERRI, 2009).

Embora tendo contribuído para integrar espaços antes isolados, consolidar a fronteira agrícola e estruturar o mapa regional, relata o mesmo autor que por diferentes razões esses processos ocorreram em meio a enormes desigualdades regionais, em razão de desequilíbrios e antigos privilégios, acarretando na constituição de um mapa de disparidade composto por regiões muitas ricas e regiões de extrema pobreza.

Os anos noventa foram palco da emergência de uma retomada do debate político e acadêmico sobre desenvolvimento rural. Das discussões surgidas na época foi criado o Programa Nacional de Fortalecimento da Agricultura Familiar (Pronaf), cuja implementação exigiu a criação de Conselhos Municipais de Desenvolvimento Rural (Cmdr) com o objetivo de gerir os recursos. Nos anos dois mil, em função da constatação dos limites para que a agricultura e os municípios conseguissem efetivamente promover o desenvolvimento rural, surgiu a emergência da abordagem territorial (FAVARETO, 2010).

Nesse sentido, foi criada a Secretaria de Desenvolvimento Territorial (SDT), como parte do Ministério do Desenvolvimento Agrário (MDA), e formulado o Programa Nacional de Desenvolvimento Sustentável de Territórios Rurais (Pronat) (CORRÊA, 2009), derivado do antigo Pronaf, em vigor no período de 1997 a 2002. A compreensão era a de que as políticas públicas para o meio rural deveriam ser planejadas numa escala mais ampla que o município (OLIVEIRA, 2014).

Rev. Eletrônica Mestr. Educ. Ambient. Rio Grande, v. 36, n. 2, p. 146 -166, mai./ago. 2019. 
Embora tenha sido criado em 2003, no início do governo do presidente Luiz Inácio Lula da Silva (SILVA JUNIOR, 2015), o Pronat só passou a atuar de forma regulamentada com a publicação da Portaria $n^{\circ}$ 05, de 18 de julho de 2005 (LEITE et al., 2009).

A concepção do Pronat foi promover o processo de construção e implantação de Planos Territoriais de Desenvolvimento Rural Sustentável (PTDRS) de regiões onde predominassem agricultores familiares e beneficiários da reforma agrária. Desse modo, a partir da sua institucionalização foram definidos os territórios passíveis de serem alvos das políticas públicas (CORRÊA, 2009).

Conforme afirma a autora os territórios da cidadania surgem como um subproduto do Pronat, uma vez que os territórios rurais selecionados em seu âmbito para serem beneficiários de políticas públicas específicas foram os que apresentavam os menores índices de desenvolvimento e as piores condições de vida.

No intuito de concretizar essa ideia, no ano de 2003 o MDA iniciou o processo de conformação de territórios rurais e instituiu órgãos colegiados como a CIAT e o Colegiado de Desenvolvimento Territorial (Codeter), além de fortalecer os Conselhos Estaduais de Desenvolvimento Rural (Cedr) e os CMDR (OLIVEIRA, 2014).

Cabe destacar, que embora tenha recebido críticas o Pronat representou o marco de uma nova modalidade de política nacional, a chamada política territorial (VISÚ, 2014), representando uma estratégia inovadora no sentido de reformular e implementar políticas públicas que abandonam a limitada visão setorial do campo e passam a considerar suas múltiplas dimensões (SILVA JUNIOR, 2015).

Segue comentando o mesmo autor que essa ideia inspirou a formulação do PTC, que surge no ano de 2008, por força do Decreto $\mathrm{n}^{\circ} 11.503$ de 25 de fevereiro desse mesmo ano, como um componente fundamental da agenda social do governo Federal. OPrograma teve sua implantação precedida por um fluxo de debates organizados por universidades, institutos de pesquisa e organismos internacionais os quais forneceram elementos atualizados sobre as condições das políticas disseminadoras da abordagem territorial no Brasil.

Como um de seus objetivos era universalizar as políticas sociais em torno de um planejamento territorial seriam construídos Planos Territoriais de Desenvolvimento Rural Sustentável (PTDRS) específicos para cada território e elaborado com a participação de colegiados territoriais, compostos pelas três esferas governamentais e pela sociedade. Tal processo asseguraria o cumprimento de uma agenda pactuada entre todos os envolvidos e 
valorizaria os pressupostos da multidimensionalidade, das múltiplas escalas de poder, além de estar calcado na ampla participação popular (SILVA JUNIOR, 2015).

Foram critérios utilizados na seleção dos Territórios da Cidadania, segundo Leite $e t$ al. (2009): a) menor Índice de Desenvolvimento Humano (IDH); b) maior concentração de agricultores familiares e assentados da Reforma Agrária; c) maior concentração de populações quilombolas e indígenas; d) maior número de beneficiários do Programa Bolsa Família; e) maior número de municípios com baixo dinamismo econômico; f) menor organização social; g) pelo menos um território por estado da federação.

Os cinco primeiros estados a incorporarem abordagem territorial e os PTDRS na construção de propostas e ações para composição de seus Planejamentos Plurianuais (PPA) (2012-2015) foram Ceará, Bahia, Piauí, Rio Grande do Norte e Sergipe. Posteriormente, no segundo ciclo de planejamento territorial, outros governos estaduais passaram a adotar essa abordagem territorializando seus estados para a realização do planejamento de suas ações (SANTOS, 2009).

O estado de Sergipe possui quatro Territórios da Cidadania (Alto Sertão, Baixo São Francisco, Sertão Ocidental e Sul Sergipano), como se verifica na figura 1, a seguir.

Figura 1 - Territórios da Cidadania em Sergipe.

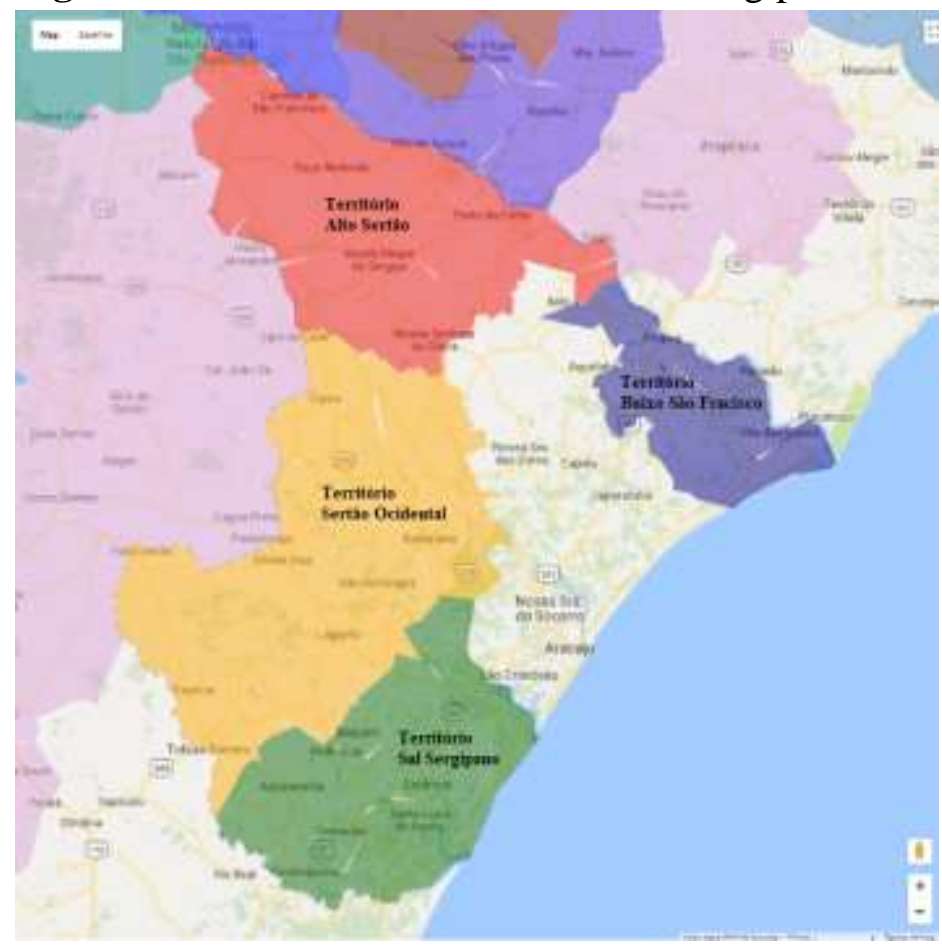

Fonte: MDA (2016). 
O primeiro território sergipano a compor o Programa foi o Alto Sertão, que abrange 7 municípios, ocupa uma área de $4.908,2 \mathrm{Km}^{2}$ e comporta uma população de 146.479 habitantes, assim distribuídos: 68.339 na zona urbana (46.65\%) e 78.140 na zona rural (53.35\%). Conta com 3.564 famílias assentadas, 12.833 estabelecimentos da agricultura familiar e 37.179 pessoas ocupadas na agricultura familiar (MDA, 2016).

Embora conviva com a seca, o território Alto Sertão Sergipano se destaca por ser constituído por sub-bacias do rio São Francisco, a saber: a sub-bacia do Curituba no município de Canindé do São Francisco; a subbacia das Onças, localizada nos municípios de Canindé do São Francisco e Poço Redondo; a sub-bacia do rio Jacaré, ocupando parte do município de Canindé e Poço Redondo; a subbacia de Campos Novos que abrange parte dos municípios de Poço Redondo e Porto da Folha, e, entre estas se destaca a maior das sub-bacias, a da Capivara que tem 1.897,7 $\mathrm{km}^{2}$ abrangendo os municípios de Porto da Folha, Monte Alegre de Sergipe, Gararu e Nossa Senhora da Glória (SILVEIRA, 2005 apud MOREIRA, 2016).

Santos e Gois (s/d) afirmam que a preocupação em dar organicidade ao Programa esteve presente desde o início da formação desse território. Nesse sentido, foi projetado um mecanismo de coordenação e gestão que possibilitasse o acompanhamento efetivo das ações em implementação, por meio da criação de uma estrutura colegiada composta por dois Grupos de Trabalho (GT) - Um deles voltado para o desenvolvimento econômico e produtivo e o outro voltado para o desenvolvimento social, responsáveis pelo acompanhamento das ações direcionadas à organização sustentável da produção e aos direitos e desenvolvimento social, respectivamente, atuando de forma articulada.

Ao todo, relatam as autoras, foram realizados sete debates territoriais, com a participação de organizações governamentais e não governamentais, onde foram contempladas as sete grandes ações do programa, identificando áreas prioritárias para implementação das ações, definindo estratégia de integração das ações do PTC com ações de outros programas e projetos; definição de estratégia de qualificação das ações - meios para capacitar as pessoas com vistas à continuidade do processo, preocupando-se com o protagonismo dos sujeitos sociais, com o controle social das ações e estudo da possibilidade de constituição de um comitê gestor e/ou metodológico.

Estendendo-se por uma área de $6.683,8 \mathrm{Km}^{2}$, o território Sertão Ocidental abrange 19 munícipios que juntos comportam uma população de 455.467 habitantes, sendo 262.397, o equivalente a $57.61 \%$ do total de habitantes, alocados na zona urbana e 193.070, o equivalente a $42.39 \%$ do total de habitantes, residentes na zona rural. O número

Rev. Eletrônica Mestr. Educ. Ambient. Rio Grande, v. 36, n. 2, p. 146 -166, mai./ago. 2019. 
de famílias assentadas corresponde a 1.471 e o de estabelecimentos da agricultura familiar a 38.698, registrando-se um total de 95.369 pessoas com essa ocupação (MDA, 2016).

Os debates para concepção do PTDRS do Território da Cidadania Sertão Ocidental foram iniciados no ano de 2005, visando a elaboração de um documento propositivo, e contou com a participação doCedr, do Departamento Agropecuário de Sergipe (Deagro), da Embrapa, da Fetase, da UFS, da Sociedade de Apoio Sócio Ambientalista e Cultural (SASAC), da Empresa de Desenvolvimento Sustentável de Sergipe (Pronese), do MST e de comunidades quilombolas (SANTOS, 2014).

Segue relatando o autor que até 2008 o território era composto por onze municípios. Porém, logo após a formulação do PTC, por meio do Decreto $\mathrm{n}^{\circ} 11.503 / 08$, aderiram ao Programa Riachão do Dantas, Areia Branca, Campo do Brito, Itabaiana, Lagarto, Malhador, Moita Bonita e São Domindos, totalizando dezenove municípios os quais compõem um mosaico territorial bastante heterogêneo, haja vista agrupar tantolocalidades do agreste como localidades do centro sul sergipano, fator que dificulta a elaboração de planos, tais como o de Cadeia Produtiva, o Safra e o próprio PTDRS.

Entre as inúmeras dificuldades e obstáculos vivenciados no início das atividades no território, chamava atenção o fato das pessoas não entenderem direito o que era territorialidade. Por essa razão, embora as ações fossem amplamente discutidas, muitos pensavam apenas em seu município e o governo queria a todo o custo ser maioria. As prefeituras não se sentiam parte do programa e não abraçavam o novo modelo por não serem as proponentes ou executoras das ações, chegando a dificultar a realização das plenárias nas sedes dos municípios (SANTOS, 2014).

O Território Baixo São Francisco é composto por 14 municípios, os quais ocupam conjuntamente uma área total equivalente a $1.967,1 \mathrm{Km}^{2}$. Sua população é de 125.174 habitantes, sendo 72.655 (58.04\%) residentes na zona urbana e 52.519 habitantes $(41.96 \%)$ residentes na zona rural. Nesse território o número de famílias assentadas corresponde a 907, o número de estabelecimentos da agricultura familiar é de 6.900 e o de pessoas ocupadas na agricultura familiar é de 21.399 (MDA, 2016).

O Território da Cidadania Baixo São Francisco é composto por 14 dos 25 municípios sergipanos que constituem a bacia do Rio São Francisco, sendo eles: Amparo de São Francisco, Brejo Grande, Canhoba, Cedro de São João, Ilha das Flores, Japoatã, Malhada dos Bois, Neópolis, Pacatuba, Propriá, Santana do São Francisco, São Francisco, Telha e Muribeca. Juntos esses municípios abrangem uma área de 1.967,10 Km² e possuem uma população de 125.174 habitantes (OLIVEIRA et al, 2016). 
Entre os principais problemas presentes nesse território estão aqueles relacionados à pesca, à agricultura e à erosão, que afeta diretamente as populações ribeirinhas. Dos quatro Territórios da Cidadania de Sergipe o Baixo São Francisco é aquele onde o Programa mais demorou para ser, de fato, incorporado e posto em prática. As fontes de informação a seu respeito são escassas e poucos foram os avanços, em comparação com os outros três territórios.

O Território Sul Sergipano agrega 12 municípios e compreende uma área de $3.950,9 \mathrm{Km}^{2}$. Sua população total é de 278.955 habitantes que estão distribuídos da seguinte forma: 155.255 habitantes $(55.66 \%)$ na zona urbana e 123.700 habitantes (44.34\%) na zona rural. As famílias assentadas correspondem a 1.256, o número de estabelecimentos da agricultura familiar é 20.599 e o número de ocupados com essa atividade é de 45.848 pessoas (MDA, 2016).

O Território da Cidadania Sul Sergipano foi instituído no ano de 2008, a partir de uma reformulação do Território Rural Centro-Sul de Sergipe. Composto de doze municípios, tem como principais características a produção de laranja para a agroindústria local, a pecuária extensiva e o extrativismo da mangaba no litoral, além da produção de coco, mandioca, manga, fumo, maracujá, feijão e milho (SILVA et al., 2017).

Assinalam os autores que em termos de indicadores socioeconômicos esse território pode ser dividido em pelo menos dois agregados municipais. O primeiro inclui os municípios de Estância, Itaporanga D’Ajuda, Salgado e Boquim, com os melhores indicadores, enquanto o segundo inclui os demais municípios que são caracterizados pelo baixo IDHM Educação e alta taxa de analfabetismo, entre 18 e 24 anos.

Durante os primeiros anos do CT nesse território as principais deliberações voltavam-se à elaboração de propostas para atender a chamadas de programas federais, tais como o Proinf e o Programa de Aceleração do Crescimento (PAC). E embora também tenha sido ponto de pauta do território a organização do colegiado, os mecanismos de gestão e a análise do regimento interno, o PTDRS somente foi concluído e tornado público em abril de 2017 (SILVA et al., 2017).

Quando da sua implantação no estado de Sergipe, o PTC contemplou 52 municípios, os quais perfazem juntos uma área de $17.508 \mathrm{~km}^{2}$. Os recursos iniciais destinados aos quatro territórios (Alto Sertão, Sertão Ocidental, Baixo São Francisco e Sul Sergipano) foram na ordem de $\mathrm{R} \$ 516.662 .361,29$, investidos em ações relativas a temas como direitos, desenvolvimento social, organização sustentável da produção, saúde, 
saneamento e acesso a água, educação e cultura, apoio à gestão territorial e infraestrutura (SOBRAL; GOMES, 2013).

A população residente na área de atuação do programa em Sergipe totaliza aproximadamente 1.006.075 habitantes, sendo 447.429 deles residentes na zona rural. $\mathrm{O}$ Índice de Desenvolvimento Humano (IDH) médio/ano desses territórios é consideravelmente baixo $(0,60)$. Entretanto, o Território do Alto Sertão é o que apresenta menor IDH $(0,58)$ (SOBRAL; GOMES, 2013).

\section{O papel dos colegiados na gestão dos PTDRS}

Pelo fato de ser pautada na articulação interinstitucional e na gestão social, a política de desenvolvimento territorial tem nos CT o principal fórum para operacionalização das ações nos territórios, se constituindo de acordo com Echeverri (2009, p. 97), “[...] o eixo central da gestão territorial e instância institucional em que a participação é feita e em que se realiza o ciclo de gestão territorial".

Como esclarece Bitencourt (2015), a gestão social busca a participação coletiva livre de coerção em que todos possam se manifestar, constituindo-se um campo de informação científica com embasamentos teórico-metodológicos, cujo êxito dos processos privilegia a participação dos agentes sociais. Nesse sentido, a gestão social, que no caso dos TC se exprimem por meio dos colegiados, representa importante mecanismo para exercitar a gestão das ações materializadas nos territórios, haja vista a diversidade de representações e a multiplicidade de papéis a ela atribuídos.

Os colegiados são compostos por vários segmentos da sociedade civil organizada, como associação de pequenos agricultores, instituições de microcrédito, representantes de instituições (como prefeituras), instituições bancárias, sindicatos de trabalhadores rurais, etc. A eles cabe o papel de definir, orientar e negociar as iniciativas para implementação das políticas públicas para o desenvolvimento rural do território. Para isso, conta com as seguintes instâncias de funcionamento: Plenário, Núcleo Dirigente e Núcleo Técnico. Para ampliar o processo de ação e participação também podem ser constituídas Câmaras Temáticas ou Técnicas e Comitês Setoriais, Comitês Temáticos ou Técnicos. O Plenário é a instância máxima do Colegiado Territorial, sendo composto pela própria composição do colegiado (SANTOS, 2014).

No que se refere aos PTDRS, esse representa o instrumento central de articulação e coordenação para o desenvolvimento e implementação da estratégia dos projetos 
territoriais em suas diferentes escalas visando à dinamização socioeconômica e sustentável dos territórios (BRASIL, 2010, p. 35). Dadas essas características o Plano representa um instrumento essencial ao monitoramento e avaliação das ações por parte do Colegiado Territorial.

Dada sua importância, o PTDRS deve integrar uma visão ampla do território, projetando todas as ações necessárias ao alcance do desenvolvimento sustentável do território, independentemente das fontes de financiamento ou parcerias a serem formadas, sejam elas de natureza pública ou privada, dentro ou fora do espaço territorial. O importante é cumprir o papel de auxiliar na gestão social, permitindo aos atores sociais e ao Estado negociar técnica e politicamente com todas as instâncias a viabilização das ações projetadas (ADIB, 2005).

Conforme menciona o autor, a elaboração do plano é de responsabilidade do CT. Porém, o documento deve expressar a síntese das decisões alcançadas pelo conjunto dos atores sociais, em conjunto com os entes públicos, durante o processo de planejamento do desenvolvimento territorial. Torna-se, a partir de então, um dos instrumentos para a gestão participativa do território, pois contém as diretrizes e estratégias que nortearão os rumos do desenvolvimento sustentável.

Assim, os PTDRS se apresentam como importante instrumento para a gestão ambiental do território, uma vez que possibilitará lançar as bases de uma Política de Desenvolvimento Rural Sustentável, contribuindo para o desenvolvimento econômico, a melhoria na qualidade das comunidades rurais, a valorização do patrimônio cultural e a proteção dos bens naturais. E embora sua construção seja coletiva, caberá ao CT, composto pelas três esferas governamentais e pela sociedade, o papel de implementá-lo (SANTOS, 2012).

Tal desafio, porém, prescinde da real internalização dos preceitos do desenvolvimento sustentável e de um criterioso e detalhado inventário dos recursos locais, capaz de transformar aspectos negativos em novos projetos de desenvolvimento, fazendose também necessário intensificar o intercâmbio entre os diversos agentes (pesquisadores, associações civis, empresas privadas, agentes financeiros e órgãos públicos) (BONNAL et al., 2011).

Brito (2013), chama atenção para o fato de apesar dos sérios problemas ambientais no meio rural, a exemplo de desmatamentos, terras degradadas e desertificadas, assoreamento dos rios, contaminação do solo e lençol freático, entre outros, tanto as ações desenvolvidas quanto o montante investido nessa dimensão são inexpressivos. Adverte 
ainda que a escassez de ações voltadas às questões ambientais, aliada aos baixos índices relacionados à gestão ambiental dos territórios, pode comprometer a estratégia de desenvolvimento territorial sustentável propagada pelo PTC, na qual devem ocorrer a integração de políticas públicas a partir de planejamento territorial e a ampliação dos mecanismos de participação social na gestão das políticas públicas.

Os resultados da análise realizada pela autora nos territórios da cidadania do estado do Ceará indicaram que a maior parte das ações ambientais implementadas no âmbito do Programa restringiram-se ao licenciamento e ao manejo de recursos naturais e voltaram-se para os assentamentos rurais de reforma agrária. Embora seja um fator limitante ao desenvolvimento rural sustentável, o avanço da desertificação nas áreas rurais do estado não tem sido tratado diretamente pelo PTC.

\section{Metodologia}

Dadas as características do tema abordado, optou-se nesta pesquisa por desenvolver uma investigação de caráter exploratório, haja vista a finalidade de analisar a influência do perfil dos membros dos CT para a priorização de ações ambientais na matriz dos Planos territoriais. Triviños (1987) reconhece nos estudos exploratórios uma forma do pesquisador aumentar sua experiência em torno de determinado problema e avançar na explicação e compreensão da totalidade do fenômeno, sua dinâmica e relações no contexto estudado.

Quanto aos procedimentos operacionais, fez-se uso da pesquisa documental e bibliográfica e para a coleta de dados empregou-se como instrumento a entrevista semiestruturada, aplicada junto aos representantes dos colegiados dos quatro territórios que representam a amostra com o objetivo de captar suas experiências no que diz respeito ao envolvimento com as questões ambientais.

Conforme Triviños (1987), uma das vantagens da entrevista semi-estrurada é possibilitar que o informante discorra sobre suas experiências a partir do foco principal proposto pelo pesquisador, permitindo respostas livres e espontâneas.

A população amostra, intencional, foi composta pelo presidente e por mais dois membros de cada CT, sendo um representante do poder público e outro da sociedade civil, tendo como critérios para a escolha desses últimos estarem participando a mais de dois anos do colegiado, serem assíduos e demonstrarem uma postura proativa frente às ações do programa. A opção por três membros de cada grupo deveu-se à necessidade de captar de 
forma mais clara e diversa a realidade dos quatro territórios, valorizando as experiências diferenciadas de cada uma das esferas.

A análise quali-quantitativa tomou como base os dados constantes nos planos de cada um dos territórios analisados, consubstanciada com as informações obtidas nas entrevistas, nos relatórios de execução do programa e na literatura usada como referência.

Para facilitar a interpretação dos dados obtidos, seguiu-se a metodologia de análise de conteúdo, ferramenta desenvolvida durante a Segunda Guerra Mundial com o objetivo de sintetizar e compreender o conteúdo dos argumentos utilizados por jornais opositores, assim como pelas propagandas inimigas. Posteriormente esse instrumento passou a ter aplicação em estudos acadêmicos de comunicação política, tendo aos poucos ocupado espaço em outras áreas, de forma que atualmente tem sido especialmente relevante para pesquisadores que atuam nas áreas de comunicação social, jornalismo, marketing, mídias sociais e correlatas (CARLOMAGNO; ROCHA, 2016).

Ainda de acordo com os autores, a metodologia de análise de conteúdo se destina a classificar e categorizar qualquer tipo de conteúdo, reduzindo suas características a elementos-chave, de modo com que sejam comparáveis a uma série de outros elementos, sendo etapas essenciais ao seu processo o planejamento, a coleta e a sistematização dos dados, constituindo-se a coleta como uma das fases mais importantes, uma vez que as demais fases de cunho analítico dependem da sua adequação.

As orientações acima serviram de norte para a seleção das seguintes categorias analíticas: solo, água, vegetação, ações preventivas, saneamento e resíduos sólidos. A opção por tais categorias levou em consideração a existência de termos (elementos-chave) que se repetiam, com certa regularidade, em cada uma das ações constantes dos PTDRS dos diferentes territórios. A partir da identificação desses elementos fez-se a classificação das ações voltadas aos diferentes temas ambientais, nominando em seguida as seis categorias a serem analisadas, priorizando-se aquelas que mais prevaleceram, a partir das quais procedeu-se o agrupamento por categorias, selecionando-se aquelas que se apresentam como elementos-chave dentro do tema objeto da investigação, como se verifica a seguir:

- Solo: reuniu ações referentes a estratégias voltadas à recuperação e manejo do solo, contenção da erosão e uso de agrotóxicos.

- Água: reuniu ações referentes a estratégias voltadas à revitalização de corpos d'água, preservação de nascentes, recuperação de matas ciliares e gerenciamento dos corpos hídricos.

Rev. Eletrônica Mestr. Educ. Ambient. Rio Grande, v. 36, n. 2, p. 146 -166, mai./ago. 2019. 
- Vegetação: reuniu ações referentes a estratégias voltadas à contenção do desmatamento, recuperação florestal de áreas degradadas, preservação da vegetação nativa.

- Fauna: reuniu ações referentes a estratégias voltadas à preservação da fauna e ao combate à caça e à pesca predatória.

- Ações Preventivas: reuniu ações referentes a estratégias voltadas à educação ambiental, fortalecimento da agroecologia e fiscalização.

- Resíduos Sólidos: reuniu ações referentes a estratégias voltadas à gestão dos resíduos sólidos, efetivação dos consórcios de resíduos sólidos e capacitação dos catadores de materiais recicláveis.

- Saneamento:reuniu ações referentes a estratégias voltadas à implantação de sistemas de redes de drenagem de águas pluviais, implantação de redes de coleta e tratamento de esgoto sanitário.

\section{Resultados e discussão}

A figura 2, a seguir, representa a síntese das ações contempladas dos quatro TC de Sergipe, conforme as categorias de análise selecionadas.

Figura 2 - Ações ambientais contempladas nos Territórios da Cidadania de Sergipe.



Fonte: Elaboração própria (2019). 
Territórios da Cidadania Alto Sertão- ao analisar a matriz de ação referente à dimensão ambiental contidas nos PTDRS desse territórioconstatou-se que a categoria água foi a que mais se destacou, enquanto que as ações voltadas à categoria resíduos sólidos foi a que menos apareceu. Foram ações relacionadas à água contempladas nesse TC: revitalização do rio São Francisco, desobstrução de nascentes, desocupação das construções nas áreas de várzeas, recuperação das matas ciliares e gerenciamento dos recursos hídricos. As ações constantes das categorias saneamento, vegetação e fauna também tiveram níveis muito baixos de indicação, enquanto que as categorias solo e ações preventivas atingiram tiveram um nível de indicação razoável, podendo ser considerado bom.

Percebe-se, em primeira análise, que embora o território tenha priorizado ações condizentes com as características ambientais da região, a seleção não levou em conta uma análise sistêmica dos problemas locais, haja vista se tratar o bioma caatinga do menos preservado do país, estando o desmatamento associado ao processo de desertificação. Parte da mata original desse território foi suprimida para uso na produção clandestina de carvão vegetal ou transformada em pasto. Segundo informações do INPE, utilizando dados referentes aos anos de 2013/2014 obtidas do satélite Landsat-8:, apenas 39,98\% da caatinga existente no país encontra-se preservada. Além disso, afauna e flora desse bioma são únicas. Estima-se que pelo menos 932 espécies já foram registradas para a região, das quais 380 são endêmicas.

Foram cursos/eventos frequentados pelos membros do CT nos últimos anos: as Caravanas Agroecológicas e Culturais organizadas pelas instituições, redes e movimentos que compõem a Rede Sergipana de Agroecologia, dentre elas o Núcleo de Agroecologia da Embrapa, o curso de técnicas de convivência com o Semiárido, o curso de Produção Integrada e sustentável (PAIS) e a reunião realizada em 2015 com a presença do então ministro do Desenvolvimento Agrário, Patrus Ananias, onde se abordou temas voltados a uma melhor convivência com a seca. Um dos entrevistados mencionou que não exatamente em 2018, mas que de 2015 a 2017 participou da Conferência Territorial e da Conferência de ATER, baseada nos princípios da agroecologia e do fortalecimento das cadeias produtivas predominantes na agricultura familiar.

Território da Cidadania Sertão Ocidental - os dados constantes do PTDRS revelam que a maior preocupação desse território está voltada para as ações preventivas. Foram ações preventivas eleitas nesse território: priorização de políticas públicas voltadas 
ao incentivo à agroecologia, unificação dos conselhos que tenham interface com a questão ambiental, desenvolvimento da educação ambiental nas áreas urbanas e rurais, promoção de cursos de capacitação na área ambiental, elaboração de projetos voltados à sustentabilidade ambiental.

Um dos entrevistados afirmaramparticipar do comitê estadual de resíduos sólidos representando o TC. Esse mesmo informante afirma ter participado, em 2016, de três eventos voltados à questão ambiental. Foram eles: plenárias sobre os consórcios Intermunicipais de Resíduos sólidos em Itabaiana e Lagarto e da plenária estadual sobre os consórcios Intermunicipais de Resíduos sólidos, em Aracaju. Como se verifica, em comparação com o Território Alto Sertão, os membros do CT do Sertão Ocidental são mais qualificados do ponto de vista ambiental.

Território da Cidadania Baixo São Francisco - a categoria que mais se destaca é a vegetação. Categorias como solo, saneamento e resíduos sólidos apresentam baixa indicação, enquanto as categorias água e fauna têm indicação regular. Foram ações priorizadas nesse território da cidadania na categoria vegetação: recuperação da mata ciliar, produção de sementes criolas, implantação de projetos que incentivem a plantação de hortaliças, a preservação dos mangues, a recuperação da área de reserva de eucalipto dos artesãos, e o combate ao desmatamento.

Nenhum dos membros entrevistados nesse TC faz parte de algum dos fóruns/entidades com interface com as questões ambientais, tampouco participaram de cursos/eventos voltados a essa temática.

Território da Cidadania Sul Sergipano - A partir dos dados constantes do PTDRS do Território da Cidadania Sul Sergipano, pode-se afirmar que a categoria que mais se destaca é ações preventivas. Conquanto as ações preventivas atingiram um nível alto de indicação, as categorias solo e vegetação obtiveram baixa representatividade, sendo considerada regular. Já as categorias saneamento, resíduos sólidos, água e fauna não pontuaram nesse território. São ações ambientais contempladas no PTDRS: fortalecimento dos intercâmbios e mutirões relacionados a experiências agroecológicas, fortalecimento das feiras da agricultura familiar no território, melhoria do aproveitamento da escola agrícola do território, promoção de práticas agroecológicas, incentivo à produção familiar de base ecológica. 
Embora a pontuação desse CT no que diz respeito às ações ambientais, propriamente ditas, tenha sido de regular a baixa, esse território tem uma longa trajetória de atuação na temática ambiental. Questões voltadas ao uso de agrotóxico, produção de adubo orgânico, canteiro econômico e biofertilizante há muito constam da sua pauta de discussão.

Assim, é possível que ao priorizar as ações preventivas o CT tenha objetivado minimizar os eventos adversos que se apresentam com potencial para ocasionar danos ambientais, uma vez que este tipo de medida procura anteceder a ocorrência do impacto negativo poupando recursos com ações mitigadoras ou compensatórias.

Um dos entrevistados disse compor o Conselho de Meio Ambiente de seu município, porém, no último ano não participou de nenhum curso/evento voltado à questão ambiental.

\section{Considerações finais}

A pesquisa revelou que embora haja similaridade entre algumas ações ambientais contempladas nas matrizes constantes nos quatro territórios da cidadania de Sergipe, cada um deles guarda particularidades que dizem respeito especialmente às características e potencialidades de cada local.

O Território da Cidadania Alto Sertão demostra alto grau de priorização de ações ambientais relacionadas às temáticas solo, água e ações preventivas e baixo grau de priorização de ações ambientais relacionadas a temas como vegetação, fauna, resíduos sólidos e saneamento.

No Território da Cidadania Sertão Ocidental verifica-se alto grau de priorização de ações ambientais relacionadas a ações preventivas e baixo grau de priorização de ações ambientais voltadas aos demais componentes: solo, água, vegetação, fauna, resíduos sólidos e saneamento.

O Território da Cidadania Baixo São Francisco demostra alto grau de priorização de ações ambientais relacionadas a vegetação, médio grau de priorização de ações ambientais relacionadas a água e à fauna e baixo grau de priorização de ações ambientais voltadas ao solo, às ações preventivas, aos resíduos sólidos e ao saneamento.

No Território da Cidadania Sul Sergipano verifica-se alto grau de priorização de ações ambientais relacionadas às ações preventivas, médio grau de priorização de ações 
ambientais relacionadas ao solo e vegetação e baixo grau de priorização de ações votadas aos demais componentes: água, fauna, resíduos sólidos e saneamento.

Cabe chamar atenção para o fato de no caso do Alto Sertão e do Sertão Ocidental, além das ações preventivas, ficar evidente a preocupação com a escassez hídrica. Ambos os territórios contemplaram o Baixo São Francisco, indicando ações voltadas à manutenção e recuperação do rio. Já o território Sul Sergipano destaca em sua matriz aspectos relacionados ao fortalecimento da agricultura orgânica e agroecologia, haja vista ser um território onde uma das principais fontes de renda provém da agricultura familiar.

As ações de saneamento e resíduos sólidos não apresentaram estratégias diferenciadas, praticamente se repetem nos territórios, deixando claro a inexistência de ações que levam em conta as particularidades locais, aspecto de suma importância, considerando-se que cada território é uno, que em cada localidade há uma maneira particular do homem se relacionar com a natureza e que cada comunidade possui experiência própria no uso e no manejo dos bens ambientais.

Por fim, a pesquisa revelou que o Colegiado Territorial Sertão Ocidental é o que concentra maior número de membros envolvidos com a questão ambiental, podendo esse dado ter contribuído para as ações selecionadas, vindo a confirmar a problemática eleita na pesquisa.

\section{Referências}

ADIB, Renaul Alberto. Plano territorial de desenvolvimento rural sustentável: guia de planejamento. Brasília: SDT/MDA, 2005.

BITENCOURT, Daniela Venceslau. Administração e gestão social: aspectos dimensionais do desenvolvimento sustentável em municípios sergipanos. 2015, $112 \mathrm{f}$. Tese (Doutorado em Desenvolvimento e Meio Ambiente) - Universidade Federal de Sergipe. Sergipe, 2015.

BONNAL, Philippe et al. Subsídios metodológicos ao estudo do desenvolvimento territorial rural, p. 35-60. In: Políticas públicas, atores sociais e desenvolvimento territorial no Brasil, Série desenvolvimento rural sustentável, Carlos Miranda e Breno Tiburcio (organizadores), v.14, Brasília: IICA, 2011.

BRASIL. Ministério do Desenvolvimento Agrário. Secretaria de Desenvolvimento Territorial. Plano Territorial de Desenvolvimento Rural Sustentável: guia para o planejamento territorial. Brasília: MDA/ SDT, 2010. 45 p. (Documentos de Apoio, 2). Disponível em: http://sit.mda.gov.br/download/ptdrs/ptdrs_qua_territorio063.pdf. Acesso em 21 de setembro de 2018. 
BRITO, Ana Vládia da Costa. O Programa Territórios da Cidadania e o desenvolvimento rural sustentável. Dissertação (mestrado). Programa de Pós-Graduação em Economia Rural da Universidade Federal do Ceará. 90f. Fortaleza/CE, 2013.

CARLOMAGNO, Márcio C.; ROCHA, Leonardo Caetano da. Como criar e classificar categorias para fazer análise de conteúdo: uma questão metodológica. Revista Eletrônica de Ciência Política, vol. 7, n. 1, 2016. Disponível em: <

https://revistas.ufpr.br/politica/article/view/45771/28756> Acesso em 17 de julho de 2018.

CORRÊA, Vanessa Petrelli. Desenvolvimento territorial e a implantação de políticas públicas brasileiras vinculadas a esta perspectiva. In: Regional, urbano e ambiental,IPEA, dezembro de 2009. Disponível em: $<$ http://ipea.gov.br/agencia/images/stories/PDFs/boletim_regional/091220_boletimregional 3 cap3.pdf $>$ Acesso em 07 de dezembro de 2017.

ECHEVERRI, R. Perico. Identidade e Território no Brasil. Brasília: MDA/SDT/IICA, 2009.

FAVARETO, A. Tendências contemporâneas dos estudos e políticas sobre o desenvolvimento territorial. In: Políticas de desenvolvimento territorial rural no Brasil: avanços e desafios. Brasília: IICA, 2010. p. 15-46. (Série Desenvolvimento Rural Sustentável: v. 12).

LEITE, Sérgio Pereira et al. Gestão social: reflexões e proposições, p. 95-146. In: Gestão social dos territórios, Barcelar, Tânia et al. (Organizadores). Série Desenvolvimento Rural Sustentável, v.10, Brasília: IICA, 2009.

MDA - Ministério do Desenvolvimento Agrário. Disponível em: <http://www.mda.gov.br> Acesso em 18 de setembro de 2016.

Moreira, Maria de Fátima. Participação social, movimentos sociais e desenvolvimento territorial no Alto Sertão Sergipano. Dissertação (mestrado). Programa de Pós-graduação em Serviço Social da Universidade Federal de Sergipe. 137 f. São Cristóvão, 2016.

OLIVEIRA, Luiza Zitzke. Análise do programa nacional de desenvolvimento sustentável dos territórios rurais (pronat): o caso do território Meio Oeste Contestado (SC). Dissertação (mestrado). Programa de Pós-graduação em Agroecossistemas da Universidade Federal de Santa Catarina. 213 f. Florianópolis - Santa Catarina, 2014.

OLIVEIRA, Marina de Carvalho et al. Políticas públicas de educação para grupos comunitários no baixo são francisco: tensões entre ajustamento e resistências. In: I Seminário Nacional de Sociologia da UFS. Anais...Programa de Pós Graduação em Sociologia - PPGS. Universidade Federal de Sergipe - UFS, São Cristóvão/SE, 2016. Disonível em: <https://seer.ufs.br/index.php/snsufs>. Acesso em: 14/02/2018.

SANTOS, C. L. A Política de Desenvolvimento dos Territórios Rurais e Seus Efeitos nas Dinâmicas Estruturais do Alto Sertão em Sergipe, Nordeste do Brasil. In: IV Simpósio Internacional de Geográfia Agrária e V Simpósio Nacional de Geografia Agrária, 2009, Niterói/RJ. Anais (Simpósio Nacional de Geografia Agrária ... Simpósio Internacional de Geografia Agrária. CD-Rom), 2009. 
SANTOS, Abeaci dos; GOIS, Magaly Nunes de. O território alto sertão sergipano: uma experiência de desenvolvimento territorial. S.D. Disponível em:

$<$ http://www.ts.ucr.ac.cr/binarios/congresos/reg/slets/slets-019-127.pdf $>$ Acesso em 03 de janeiro de 2018.

SANTOS, Dario Nunes dos. Documento contendo subsidio para orientar a ação da SDT/MDA na articulação com políticas públicas ambientais e nas ações de capacitação para gestão dos planos territoriais de desenvolvimento rural sustentavel PTDRS, com foco nos projetos estratégicos ambientais. Instituto Interamericano de Cooperação para a Agricultura - ICCA. 2012. Disponível em:

$<$ http://www.iicabr.iica.org.br/wp-content/uploads/2014/03/pc_produto_dario.pdf $>$ Acesso em $22 / 03 / 2018$.

SANTOS, Plínio Elkson dos. Desafios da gestão social: as experiências no território do sertão ocidental sergipano. 2014. Dissertação (mestrado) 125 f. Universidade Federal de Sergipe, São Cristóvão - SE.

SANTOS, Plínio Elkson; COSTA, José Eloízio. Desafios da gestão social do território: as experiências no território do Sertão Ocidental de Sergipe. In: NPGEO: "30 Anos de Contribuição à Geografia”. Anais...São Cristóvão/SE, 2013.

SILVA, Marcos Aurélio Santos da et al. Análise do empoderamento da sociedade civil no território rural sul sergipano por meio da análise estratégica. Revista em Gestão, Inovação e Sustentabilidade - Brasília, v. 3, n. 1, p. 101-118, dez. 2017

SILVA JUNIOR, Joaquim Alves. Desafios e perspectivas do programa territórios da cidadania: o caso do território da cidadania Vale do Ribeira. Dissertação (mestrado). Programa de Pós-graduação em Ciência Ambiental da Universidade de São Paulo. $181 \mathrm{f}$. São Paulo, 2015.

SOBRAL, Ivana Silva; GOMES, Laura Jane. Indicadores de sustentabilidade social nos projetos de assentamentos de reforma agrária em Sergipe. s/1, 2013. Disponível em: < https://dialnet.unirioja.es >. Acesso em 15 de janeiro 2018.

TRIVINÕS, Augusto Nibaldo Silva. Introdução à pesquisa em ciências sociais: a pesquisa qualitativa em educação. São Paulo, Atlas, 1987.

VISÚ, G. O programa territórios da cidadania: uma análise a partir do cone sul de Mato Grosso do Sul. Observatorio de La Economía Latinoamericana, Número 203, 2014. Disponível em: <http://www.eumed.net/cursecon/ecolat/br/14/territorio.hmtl > Acesso em 14 de janeiro de 2018.

Submetido em: 08-05-2019.

Publicado em: 